\section{Courtroom drama}

\author{
Forensic science faces rough justice on \\ both sides of the Atlantic.
}

\section{A} lthough it is better under the law that ten guilty people go free than that one innocent person be convicted - as eighteenthcentury English judge William Blackstone said - it is better still to make as few mistakes as possible. Forensic science is a powerful tool to help achieve this, but many research-based tools are not as foolproof as they are presented - both in court and in television dramas.

Just over a year ago, this journal stressed the need for more research on forensic techniques (see Nature 464, 340-342, 344-346, 347-348; 2010). In that time, the United States has taken some tentative steps forward, but the United Kingdom is about to stumble backwards.

Britain used to boast one of the great powerhouses of the forensics research world, the Forensic Science Service (FSS). A botched attempt at privatization by the former Labour government left the FSS in an unstable position, and in December last year the coalition government said that the service would close by next March, blaming ongoing losses of $£ 2$ million (US\$3.2 million) a month.

The timing is unfortunate, given that in January the UK Home Office asked its chief scientist to conduct a review of research relevant to forensic science. Although that review has asked researchers to confine submissions to a length of 1,000 words - just 200 words per question posed - the inquiry will find plenty of evidence that the loss of the FSS will undermine research on forensic techniques, and ultimately the course of justice. The government's Criminal Cases Review Commission, set up to investigate possible wrongful convictions, has already expressed its unease.

Of particular concern is the fate of the service's unique archive of more than 1.5 million records. These include evidence and forensic samples that could still be valuable for cold-case investigations as techniques improve.

At a parliamentary hearing last week, the research and development manager of the FSS, Gillian Tully, admitted that "at the moment there isn't yet a plan for what's going to happen to the archive".

In the same week, the Law Commission, an independent body created to review the laws of England and Wales, called for reform to prevent dubious scientific evidence causing miscarriages of justice. It was prompted to speak out after a number of cases in which forensic evidence used in trials was later discredited.

The commission made some good suggestions, such as allowing judges to call up their own experts to test the reliability of evidence. It is disappointing that they received only a lukewarm response from the government, which suggested that existing laws and procedures are adequate. Even if they were accepted, the Law Commission's
"A botched attempt at privatization left the UK Forensic Science Service in an unstable position." suggestions will be useless without a strong base of forensic researchers to subject tests - new and old - to scrutiny. The loss of the FSS will remove this capability. Commercial providers of forensic services do valuable work, but this is one area simply not suited to a fully commercial market. Although a combination of regulation and competition can increase scrutiny and standards, not all forensic services will be attractive to those who seek a profit.

Also, commercial operators can be reluctant to reveal full details of proprietary techniques used to analyse evidence so that they can be scrutinized by all sides in a case. Such secrecy has already led to objections from defence lawyers, and, in at least one case, a retrial. Basic research must underpin the practice of forensic science, both to bring new, evidence-based tests to market and to use publications in open and peerreviewed literature to demonstrate the reliability of techniques already in use. It requires financial — and moral — support from the government.

The United States now has a chance to give this support. Two years ago, the US National Academy of Sciences warned of the need to overhaul the country's forensic science base, and recommended the creation of a national institute of forensic science. This idea now looks dead in the water, but earlier this year Senator Patrick Leahy (Democrat, Vermont) proposed legislation that would establish something similar.

Rather than setting up an independent federal agency, Leahy's bill would create an Office of Forensic Science in the Department of Justice. A forensic science board of researchers, lawyers and other players $\rightarrow$ NATURE.COM

To comment online, go.nature.com/xhunqv click on Editorials at: would look at research priorities, and scientists overseen by the National Institute of Standards and Technology would work on research needs in individual disciplines. The idea deserves to be taken seriously. Justice for all takes effort.

\section{Welcome Nature Climate Change}

Since Nature Genetics was founded in 1992, 17 Nature-branded $\checkmark$ research journals have been launched. Most are devoted to specific disciplines (such as immunology or materials research) ranging across all the natural sciences. Some, such as Nature Photonics, also have a strong technological component. Others, such as Nature Nanotechnology, touch on all the disciplines, sometimes extending into social-science discussions. And one, Nature Communications, sets itself, like Nature, at no particular discipline or theme.

Nature Climate Change, launched this week, is something of a distinct venture. Climate change is a phenomenon that is relevant, in principle, to all research disciplines. This journal focuses as much on the impacts of climate change as on its origins and mechanisms. And for the first time within the Nature-branded stable, the journal is explicitly set up to include the social sciences within its remit, with a trained social scientist on its staff, and a panel of social-science advisers to help us to penetrate territory that lies beyond our traditional zones of engagement.

The first issue of the journal (see www.nature.com/nclimate) reflects this inclusive strategy. It covers research on aircraft contrails' impact on climate, the effects of climate change on agriculture and health, and how experience of flooding can affect public attitudes to energy use. The issue also includes journalism and commentary on decision-making and on data sharing.

In tackling such issues, Nature Climate Change sits alongside Nature Geoscience and Nature. But this is a complementary relationship and, in line with 'family' tradition, all the journals are editorially independent of each other. Nature will continue to publish the most scientifically significant research, and discussions with the broadest impact. Nature Geoscience will focus on the relevant Earth and Solar System mechanisms. And Nature Climate Change will offer new avenues for those interested in the long-term changes in our atmosphere and their impacts.

Both individually and as aroup, we hope the content and influence of these journals will significantly help our planet's inhabitants to anticipate and cope with the global changes ahead. 